\title{
Effects of ipt Gene Expression on Leaf Senescence Induced by Nitrogen or Phosphorus Deficiency in Creeping Bentgrass
}

\author{
Yan Zhang', Cuiyue Liang1, Yan Xu, Thomas Gianfagna, and Bingru Huang ${ }^{2}$ \\ Department of Plant Biology and Pathology, Rutgers University, New Brunswick, NJ 08901
}

\begin{abstract}
AdDitional INDEX words. cytokinin, isopentenyl transferase, SAG12, Agrostis stolonifera, nutrient, acid phosphatase, nitrate reductase

ABstract. The objective of the study was to determine whether the expression of a cytokinin (CK) biosynthesis gene encoding adenine isopentenyl transferase (ipt) would delay or suppress leaf senescence induced by nitrogen $(\mathrm{N})$ or phosphorus (P) deficiency in a $\mathrm{C} 3$ grass species, creeping bentgrass (Agrostis stolonifera). The ipt gene was ligated to a senescence-associated promoter, $S A G 12$, and was transferred into creeping bentgrass using an agrobacterium (Agrobacterium tumefaciens)-mediated transformation technique. Plants from an SAG12-ipt transgenic line (S41) and a null transformant (NT) control line were grown in nutrient solutions with all essential elements or without $N(-N)$ or P (-P) for 21 days. Significant declines in leaf photochemical efficiency (Fv/Fm) and chlorophyll content of mature leaves were detected in NT and SAG12-ipt plants exposed to N or P deficiency. Compared to the NT control line, SAG12-ipt plants had higher levels of Fv/Fm, chlorophyll, and CK contents in leaves, and these differences between the NT control and $S A G 12-i p t$ line became more pronounced with treatment duration. The ipt expression was detected in the $-\mathrm{P}$-treated and the $-\mathrm{N}$-treated plants after 21 days, although the level of expression decreased under $\mathbf{N}$ or $\mathbf{P}$ deficiency. Under -P treatment, root acid phosphatase activity was greater in SAG12-ipt line than in the NT control line. No significant differences in nitrate reductase activity were detected in leaves or roots between the $S A G 12-i p t$ and the NT control lines. Our results demonstrated that $S A G 12$-ipt expression suppressed leaf senescence induced by $\mathrm{N}$ or $P$ deficiency in a perennial grass species. The suppressing effects on leaf senescence under $P$ deficiency may be related to $\mathrm{CK}$ regulation of more efficient use of $\mathrm{P}$ in roots of the $S A G 12-i p t$ plants.
\end{abstract}

Leaf senescence is a natural process of leaf maturation, but it can be induced prematurely by environmental stresses. Cytokinins (CKs) have been well known for their function in delaying leaf senescence, and even in reversing the process of leaf senescence (Gan and Amasino, 1995; Smart, 1994). The involvement of CKs in leaf senescence has been studied for many years through exogenous application of this hormone (Mayak and Halevy, 1970; McGrady et al., 1986; Singh et al., 1992; Zhang and Ervin, 2008). Recently, transformation of plants with an ipt gene encoding adenine isopentenyltransferase, an enzyme that catalyzes the key step in de novo CK biosynthesis, has provided new tools for the study of regulatory roles and mechanisms of $\mathrm{CK}$ controlling leaf senescence (Medford et al., 1989). The ipt gene has been introduced into different plant species using different promoters, including constitutive and developmentally controlled promoters in various dicotyledonous plant species (Calderini et al., 2007; Chang et al., 2003; Chen et al., 2001; Cowan et al., 2005; Khodakovskaya et al., 2005; McCabe et al., 2001; Rivero et al., 2007; Swartzberg et al., 2006) and a limited number of monocot species, including rice (Oryza sativa), wheat (Triticum aestivum), tall fescue (Festuca arundinacea), and italian ryegrass (Lolium multiflorum) (Hu et al., 2005; Li et al., 2004; Lin et al., 2002; Sykorová et al., 2008). These studies demonstrate that

Received for publication 9 Dec. 2009. Accepted for publication 4 Feb. 2010. This study was supported by Rutgers Center for Turfgrass Science.

We thank Dr. Jinpeng Xing for assistance with transformation and Drs. Jiang Tian and Aifang Yang for valuable discussions regarding gene expression analysis. We also thank Dr. Chenping Xu and Emily Merewitz for critical review of the manuscript.

${ }^{1}$ These authors contributed equally to this work.

${ }^{2}$ Corresponding author. Email: huang@aesop.rutgers.edu. elevated CK levels in ipt transgenic plants resulted in suppression or delay in leaf senescence.

The ability of CKs to delay leaf senescence has great potential for improving plant productivity in agricultural systems, especially under unfavorable environmental conditions.

Various studies used senescence-associated promoters, such as SAG12 originally isolated from arabidopsis (Arabidopsis thaliana) by Gan and Amasino (1995), in ipt transformation. In the SAG12-ipt system, senescence triggers the transcription of ipt gene ligated to the $S A G 12$ promoter. The enzyme then catalyzes CK production that suppresses senescence, which in turn, attenuates SAG12-regulated ipt transcription, thus providing autoregulatory control of CK synthesis (Gan and Amasino, 1995). The SAG12-autoregulated transformation overcomes the abnormal growth problems associated with the overproduction of CKs in transgenic plants containing the ipt gene driven by constitutive promoters (Gan and Amasino, 1996; Schnablova et al., 2006). The increase in CKs production in ipt-transgenic plants has been found to contribute to enhanced stress tolerance through the regulation of leaf senescence, including drought in petunia (Petunia hybrida) (Clark et al., 2004) and tobacco (Nicotiana tabacum) (Rivero et al., 2007), flooding in arabidopsis (Huynh et al., 2005; Zhang et al., 2000), cold in tall fescue (Hu et al., 2005), and nutrient deficiency in tobacco (Jordi et al., 2000).

Leaf senescence is a typical symptom of nutrient deficiencies, such as $\mathrm{N}$ and $\mathrm{P}$, which lead to reduction in plant biomass production and even plant death (Smart, 1994; Thomas and Stoddart, 1980). Perennial grasses are widely used as turfgrasses in urban horticulture. Leaf senescence in environments with limited nutrient availability is a major factor reducing aesthetic appearance in turfgrass species. Research 
in other plant species has shown that $\mathrm{CK}$ synthesis is inhibited by $\mathrm{N}$ deficiency, which may be associated with leaf senescence (Sakakibara et al., 2006). However, whether and how increases in CKs through expression of the ipt gene could regulate leaf senescence induced by $\mathrm{N}$ or $\mathrm{P}$ deficiency in perennial grasses is not well understood. $\mathrm{N}$ or P deficiency is usually caused by low available $\mathrm{N}$ or $\mathrm{P}$ levels in the soil solution for plant uptake and/or low nutrient acquisition and assimilation capacity, which leads to growth inhibition and leaf chlorosis. Nitrate reductase (NRase) catalyses the reduction of nitrate to nitrite in $\mathrm{N}$ assimilation (Solomonson and Barber, 1990), and therefore plays a critical role in $\mathrm{N}$ utilization. Under $-\mathrm{P}$ conditions, plants show various adaptive responses, including an increase in acid phosphatase (APase) secretion (Clarkson and Lüttge, 1991). Studies indicated that APase activity in roots and the secretion of APases from the roots increase in response to P deficiency (Ni et al., 1996; Tadano and Sakai, 1991). APase activities in leaf tissues were found to be related to $\mathrm{P}$ use efficiency during development or under P stress conditions (Duff et al., 1994). We hypothesize that increases in CK levels may suppress low $\mathrm{N}$ - or P-induced leaf senescence in perennial grass plants and the effects may be related to changes in APase and NRase activities. We transformed a $\mathrm{C}_{3}$ perennial grass species, creeping bentgrass, widely used as a turfgrass in cool climatic regions, with the ipt gene ligated to the $S A G 12$ promoter. In our previous study with $S A G 12$-ipt transgenic creeping bentgrass, we found that $S A G 12$-ipt plants exhibited better heat tolerance than the null transformant control plants, which was manifested by maintaining higher chlorophyll content, more tiller production, and increased root growth when exposed to high temperature $\left(35^{\circ} \mathrm{C}\right)$ for $14 \mathrm{~d}$ (Xu et al., 2009). This study was designed to investigate whether expression of SAG12-ipt in creeping bentgrass would delay or suppress leaf senescence induced by $\mathrm{N}$ or $\mathrm{P}$ deficiency and to examine the responses of $\mathrm{CK}$ accumulation and APase and NRase activities to $\mathrm{P}$ or $\mathrm{N}$ deficiency associated with differential ipt expression in SAG12ipt transgenic creeping bentgrass and the NT control plants.

\section{Materials and Methods}

Plant materials. Plant tissue callus was derived from stolons of 'Penncross' creeping bentgrass. Transgenic plants were produced using the agrobacterium infection technique with the ipt gene (from agrobacterium) encoding adenine isopentenyl transferase ligated to a senescence-associated promoter ( $S A G 12$ ) in a pCambia1301 plasmid construct (Xu et al., 2009). Each plasmid contains the hygromycin resistance gene (hyg) for transgenic plant tissue selection, and the GUS reporter gene (uid) for identification of transgenic plants.

A SAG12-ipt transgenic line (S41) that exhibited improved heat tolerance and delayed leaf senescence under heat stress in our previous studies (Xu et al., 2009) was compared to a NT line containing the pCAMBIA1301 vector without the SAG12-ipt. The NT line that exhibited a similar growth habit to the transgenic line under normal growth conditions was chosen for comparison in this study. Plants were vegetatively propagated and established in a greenhouse with average temperatures at 21/ $14{ }^{\circ} \mathrm{C}$ (day/night) and natural sunlight at an average of 600 $\mu \mathrm{mol} \cdot \mathrm{m}^{-2} \cdot \mathrm{s}^{-1}$ photosynthetic photon flux $(P P F)$ at the canopy height, and an 11-h photoperiod. Plants were grown in $20-\mathrm{cm}-$ diameter plastic pots filled with fine sand, and were watered daily and fertilized once per week with half-strength Hoagland's solution (Hoagland and Arnon 1950). During the establishment phase, leaves were trimmed once per week to maintain a uniform canopy height of $6 \mathrm{~cm}$. After roots were fully developed (about 6 weeks after transplanting), plants were grown hydroponically in continuously aerated nutrient solution in a controlledenvironment chamber (Conviron, Winnipeg, Manitoba, Canada) at $20 / 15^{\circ} \mathrm{C}$ (day/night), a 14-h photoperiod, $500 \mu \mathrm{mol} \cdot \mathrm{m}^{-2} \cdot \mathrm{s}^{-1}$ $P P F$, and $75 \%$ relative humidity. Plants were left uncut during the treatment period. The hydroponic culture solution contained $0.32 \mathrm{~mm}\left(\mathrm{NH}_{4}\right)_{2} \mathrm{SO}_{4}, 0.48 \mathrm{~mm} \mathrm{MgSO} \cdot 7 \mathrm{H}_{2} \mathrm{O}, 0.15 \mathrm{~mm} \mathrm{~K}_{2} \mathrm{SO}_{4}$, $0.16 \mathrm{~mm} \mathrm{KNO} 3,0.32 \mathrm{~mm} \mathrm{Ca}\left(\mathrm{NO}_{3}\right)_{2} \cdot 4 \mathrm{H}_{2} \mathrm{O}, 0.3 \mathrm{~mm} \mathrm{KH_{2 }} \mathrm{PO}_{4}$, $23.64 \mu \mathrm{M}$ Fe(EDTA)Na, $5.61 \mu \mathrm{M} \mathrm{MnCl}_{2} \cdot 4 \mathrm{H}_{2} \mathrm{O}, 11.23 \mu \mathrm{M}$ $\mathrm{H}_{3} \mathrm{BO}_{3}, 0.24 \mu \mathrm{M} \mathrm{CuSO} \cdot 5 \mathrm{H}_{2} \mathrm{O}, 0.04 \mu \mathrm{M}\left(\mathrm{NH}_{4}\right)_{6} \mathrm{Mo}_{7} \mathrm{O}_{24} \cdot 4 \mathrm{H}_{2} \mathrm{O}$, and $7.09 \mu \mathrm{M} \mathrm{ZnSO} \cdot 7 \mathrm{H}_{2} \mathrm{O}$. Nutrient treatment was initiated after roots were established (about 6 weeks after transplanting). After $28 \mathrm{~d}$ of culture in the complete nutrient solution, plants were transferred into two different types of growth solution lacking $\mathrm{N}$ or $\mathrm{P}$. In the $-\mathrm{N}$ solution, $\left(\mathrm{NH}_{4}\right)_{2} \mathrm{SO}_{4}, \mathrm{KNO}_{3}$, and $\mathrm{Ca}\left(\mathrm{NO}_{3}\right)_{2} \cdot 4 \mathrm{H}_{2} \mathrm{O}$ were replaced by $0.32 \mathrm{~mm} \mathrm{~K}_{2} \mathrm{SO}_{4}, 0.08 \mathrm{~mm} \mathrm{~K}_{2} \mathrm{SO}_{4}$, and $0.32 \mathrm{~mm}$ $\mathrm{CaCl}_{2}$, respectively. $\mathrm{KH}_{2} \mathrm{PO}_{4}$ was replaced by $0.6 \mathrm{~mm} \mathrm{~K} \mathrm{SO}_{4}$ in the $-\mathrm{P}$ treatment. Each treatment was replicated in four containers. All measurements were made on the day prior to transferring plants to the $-\mathrm{N}$ or $-\mathrm{P}$ solution $(0 \mathrm{~d})$ and at 7 and $21 \mathrm{~d}$ after plants were subjected to $-\mathrm{N}$ or $-\mathrm{P}$ treatment.

EVALUATION OF LEAF SENESCENCE. At 0,7 (the first visual sign of leaf yellowing), and $21 \mathrm{~d}$ (severe leaf yellowing) of $-\mathrm{N}$ or $-\mathrm{P}$ treatment, leaf photochemical efficiency and chlorophyll content were measured to evaluate leaf senescence. Measurements were taken on fully expanded leaves.

Leaf photochemical efficiency was estimated using the ratio of variable fluorescence $(\mathrm{Fv})$ to maximum fluorescence $(\mathrm{Fm})$ measured with a chlorophyll fluorescence monitor (Hansatech Instrument, King's Lynn, UK). Leaves were adapted in darkness by enclosing in an opaque leaf clip for $30 \mathrm{~min}$ before the $\mathrm{Fv} / \mathrm{Fm}$ reading was taken.

Leaf chlorophyll was extracted from fresh leaves using dimethyl sulfoxide (DMSO). Approximately $0.5 \mathrm{~g}$ of leaves was incubated in $5 \mathrm{~mL}$ of DMSO solution for $48 \mathrm{~h}$ in darkness. The absorbance of the extracts was determined using a spectrophotometer (Spectronic Genesys2; Spectronic Instruments, Rochester, NY). Chlorophyll content was calculated based on the absorbance at 663 and $645 \mathrm{~nm}$ using the formulas described by Arnon (1949).

Determination of NRase activity and APase activity. NRase activity was determined by measuring the formation of $\mathrm{NO}_{2}{ }^{-}$. The extraction and the measurement of NRase activity were carried out according to the method of Kaiser and Brendle-Behnisch (1991) with modifications. Fresh fully expanded leaves or entire roots $(1 \mathrm{~g})$ were homogenized in liquid $\mathrm{N}_{2}$. For the activity assay, $1 \mathrm{~mL}$ of a buffer containing $50 \mathrm{~mm}$ HEPES-KOH (pH 7.6), 2 mM dithiothreitol, 0.1\% polyvinylpyrrolidone, and $15 \mathrm{~mm} \mathrm{MgCl}_{2}$ was added to frozen samples. After centrifuging at $12,000 g_{\mathrm{n}}$ for $30 \mathrm{~min}$ at $4{ }^{\circ} \mathrm{C}, 100 \mu \mathrm{L}$ of supernatant was added to $450 \mu \mathrm{L}$ of the reaction medium, containing $50 \mathrm{~mm} \mathrm{KH} \mathrm{PO}_{4}-\mathrm{K}_{2} \mathrm{HPO}_{4}, 5 \mathrm{~mm} \mathrm{KNO} 3,0.2 \mathrm{~mm}$ $\mathrm{NADH}$, and $5 \mathrm{~mm}$ EDTA. The incubation was carried out at $30{ }^{\circ} \mathrm{C}$ for $4 \mathrm{~min}$ and was stopped by the addition of $0.1 \mathrm{~mL}$ of $0.03 \mathrm{M}$ oxaloacetic acid. NRase activity was expressed as the rate of generated $\mathrm{NO}_{2}{ }^{-}$production (micromoles per milligram protein per hour).

Extraction and quantification of APase activity were performed following the method described by Yan et al. (2001) 
with modifications. Briefly, fresh fully expanded leaves or entire roots $(0.25 \mathrm{~g})$ were frozen in liquid $\mathrm{N}_{2}$, ground in a cold mortar, and macerated in $1.2 \mathrm{~mL}$ of $45 \mathrm{~mm}$ sodium acetateacetic acid (pH 5.0). The extract was then centrifuged at 12,000 $g_{\mathrm{n}}$ for $30 \mathrm{~min}$ at $4{ }^{\circ} \mathrm{C}$. A $50-\mu \mathrm{L}$ portion of the supernatant was added to the acetate-acetic acid buffer to reach a total volume of $500 \mu \mathrm{L}$. APase activity was assayed using $p$-nitrophenylphosphate as a substrate (McLachlan et al., 1987), and the activity was expressed as micromoles $p$-nitrophenyl hydrolyzed per milligram protein per minute. Soluble protein was measured according to Bradford (1976).

Determination of CK content. Fully expanded leaves were sampled at 0,7 , and $21 \mathrm{~d}$ after $\mathrm{N}$ or $\mathrm{P}$ removal for analysis of the content of three forms of CKs: trans-zeatin/zeatin riboside (Z/ZR), dihydrozeatin/dihydrozeatin riboside (DHZ/ DHZR), and isopentenyladenine/adenosine (iP/iPA). The contents of Z/ZR, DHZ/DHZR, and iP/iPA were quantified by an enzyme-linked immunosorbent assay (ELISA). Extraction and quantification of hormones followed the method described by Setter et al. (2001) with some modifications (Wang et al., 2003). Briefly, samples were extracted in $80 \%$ (v/v) methanol and purified with reverse phase $\mathrm{C}_{18}$ columns. Hydrophilic contaminants were washed out with $200 \mu \mathrm{L}$ of $20 \%$ solvent [ $20 \%$ methanol, $80 \%$ aqueous triethylamine (10 mm , pH 3.5)]. The CK-containing fraction was eluted using $200 \mu \mathrm{L}$ of $30 \%$ solvent (30\% methanol and $70 \%$ aqueous triethylamine). Monoclonal antibodies were developed by Eberle et al. (1986). An indirect competitive ELISA was used for quantification of Z/ZR, DHZ/DHZR, and iP/iPA as previously described (Setter et al., 2001).

REVERSE TRANSCRIPTASE (RT)-POLYMERASE CHAIN REACTION (PCR). The expression pattern of ipt in fully expanded leaves was determined. Equal amounts of plant sample from four replicates were mixed. Total RNA was extracted from the ground leaves of SAG12-ipt plants on each sampling date by an RNeasy kit (Qiagen, Valencia, CA). The RT-PCR analysis was repeated three times for each sampling date. DNA contamination was removed by treating the total RNA with RNase-free DNase I (Ambion, Austin, TX). The total RNA was quantified and checked for quality spectrophotometrically according to Sambrook et al. (1989). cDNA was synthesized from $2 \mu \mathrm{g}$ of total RNA from each sample using the Ready-To-Go RT-PCR kit (Amersham, Piscataway, NJ). Following the two-step protocol suggested by the manufacturer, first-strand cDNA was generated with lyophilized pd $(\mathrm{T})_{12-18}$ primer and used as a template for polymerization. cDNA template $(2 \mu \mathrm{L})$ was added to the PCR reaction with ipt gene-specific primers (5'GACC T GCA T C T A A T T T T CGGTCCA AC - 3 ' / 5 ' GGGTGCAACATCTGCTTAACTCT-3') and primers of an actin gene (5'-GATATGGAAAAGATCTGGCATCAC-3'/5'TCATACTCGGCCTTGGAGATCCAC-3'). The ipt gene-specific primers were designed based on the 723-bp agrobacterium complete sequence (gi|10955016:7864-8586) using primer3 (Invitrogen, Carlsbad, CA). The target amplicon had a size of 432 and $750 \mathrm{bp}$ in creeping bentgrass for ipt and actin gene primers, respectively. General PCR was conducted with the following program: inactivate the reverse transcriptase at $95^{\circ} \mathrm{C}$ for $5 \mathrm{~min}, 94^{\circ} \mathrm{C}$ for $1 \mathrm{~min}, 60^{\circ} \mathrm{C}$ for $1 \mathrm{~min}$, and $72^{\circ} \mathrm{C}$ for $10 \mathrm{~min}$ for 35 cycles. The PCR products were checked in a $1.5 \%$ agarose gel in $1 \times$ TAE gel buffer with ethidium bromide. The amplified cDNA fragment was extracted from the agarose gel, and was purified using QIAquick gel extraction kit (Qiagen).
The PCR product was sequenced to confirm the identity of the cDNA. Actin was used as an internal standard.

Statistical analysis. Physiological data and CK content were subjected to the analysis of variance based on the general linear model procedure of SAS (version 9.1; SAS Institute, Cary, NC). Means of four replicates were presented. The statistical significance of differences in the mean values of the examined parameters between the SAG12-ipt line (S41) and the NT line were separated by Fisher's protected least significant difference (LSD) test at $P=0.05$.

\section{Results}

EFFECT OF $\mathbf{N}$ OR $\mathbf{P}$ DEFICIENCY ON LEAF CHLOROPHYLL CONTENT AND PHOTOCHEMICAL EFFICIENCY. The SAG12-ipt plants were more vigorous with a greater density of leaves and roots than the NT control, regardless of treatment (data not shown), although when plants were grown in complete nutrient solution, no significant difference in leaf chlorophyll content (milligrams per gram fresh weight) was found between the SAG12-ipt plants and the NT control during the 21-d period (Fig. 1A). Leaf chlorophyll content of both lines decreased with -P treatment to significantly below the plants with complete
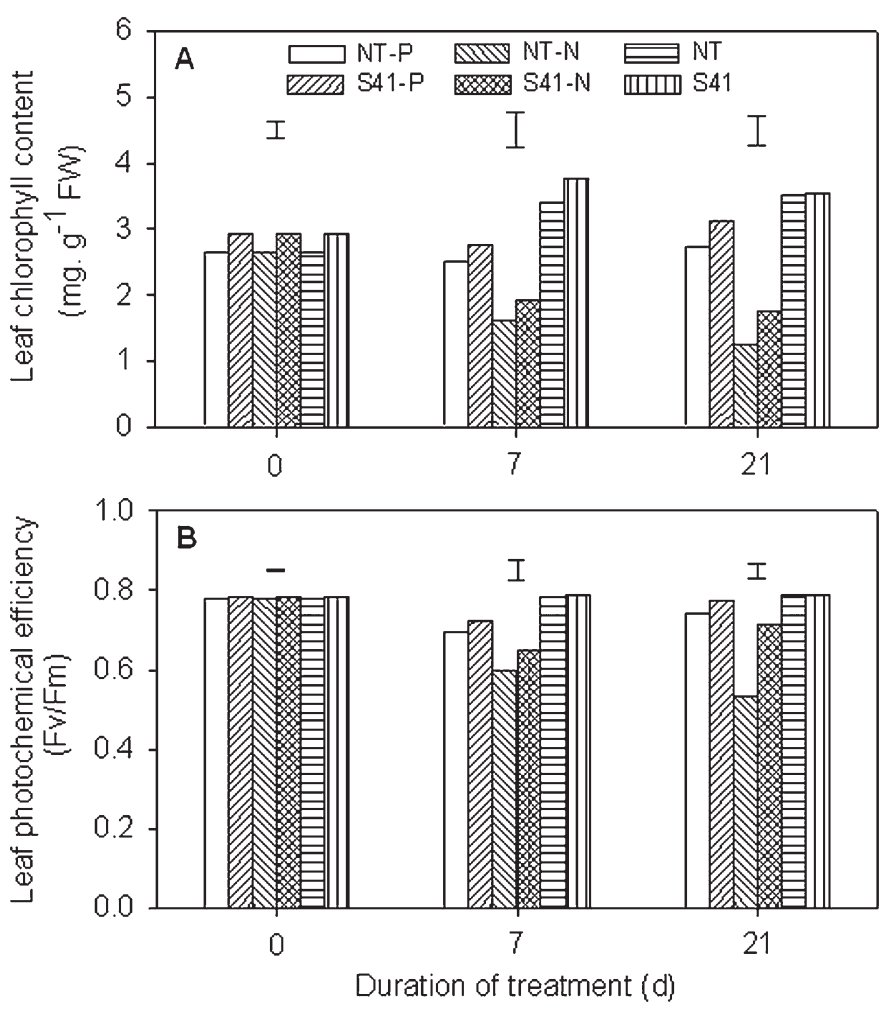

Fig. 1. Leaf chlorophyll content (A) and leaf photochemical efficiency (B) for SAG12-ipt transgenic line (S41) and the null transformant (NT) line of creeping bentgrass at 0,7 , and $21 \mathrm{~d}$ of full nutrient solution, no nitrogen $(-\mathrm{N})$, or no phosphorus (-P) treatment. S41, S41-P, and S41-N denote S41 line grown in full nutrient solution, $-\mathrm{P}$, or $-\mathrm{N}$, respectively. NT, NT-P, and NT-N denote NT line grown in full nutrient solution, $-\mathrm{P}$, or $-\mathrm{N}$, respectively. LSD $(P=$ 0.05) bars for comparisons of chlorophyll content and Fv/Fm among the treatments at a given date were present. LSD $(P=0.05)$ values for comparisons of chlorophyll content over time were $0.62,0.27,0.81,0.26,0.29$, and 0.81 for the S41-P, S41-N, S41, NT-P, NT-N, and NT, respectively. LSD $(P=0.05)$ values for comparisons of $\mathrm{Fv} / \mathrm{Fm}$ over time were $0.04,0.06,0.03$, 0.05, 0.01, and 0.04 for the S41-P, S41-N, S41, NT-P, NT-N, and NT, respectively. 
nutrient solution at $7 \mathrm{~d}$. At $21 \mathrm{~d}$ of -P treatment, the SAG12-ipt plants had similar chlorophyll content to those grown in the complete nutrient solution, but the control plants without the ipt gene had significantly lower chlorophyll content than the control plants supplied with compete nutrient solution. N deficiency caused a significant decline in chlorophyll content in NT and SAG12-ipt plants at 7 and $21 \mathrm{~d}$. The decline in the NT plants became more pronounced with treatment duration, and at $21 \mathrm{~d}$ of $-\mathrm{N}$ treatment, higher chlorophyll content was present in SAG12-ipt plants than in the NT plants (Fig. 1A). $-\mathrm{N}$-treated SAG12-ipt and NT plants had significantly lower chlorophyll content than -P-treated plants at 7 and $21 \mathrm{~d}$ of treatment.

No differences in leaf photochemical efficiency (Fv/Fm) were found between the SAG12-ipt and NT plants grown in complete nutrient solution, and $\mathrm{Fv} / \mathrm{Fm}$ did not change over time in this treatment (Fig. 1B); however, after $7 \mathrm{~d}$ in $-\mathrm{N}$ or $-\mathrm{P}$ solution, Fv/Fm decreased in both lines. The decreases were more significant in the $-\mathrm{N}$ treatment than in the $-\mathrm{P}$ treatment. The Fv/Fm of the SAG12-ipt line was not significantly different from the NT line in $-\mathrm{P}$ treatment. However, under $-\mathrm{N}$ conditions, Fv/Fm of the SAG12-ipt plants was significantly higher than that of the NT plants. At $21 \mathrm{~d}$ of treatment, Fv/Fm of the NT line continued to decrease in $-\mathrm{N}$ treatment, but remained the same in -P treatment, whereas the SAG12-ipt line remained about the same in $-\mathrm{P}$ and $-\mathrm{N}$ treatments compared to the $\mathrm{Fv} / \mathrm{Fm}$ at $7 \mathrm{~d}$. SAG12-ipt plants had over $30 \%$ higher Fv/Fm than the NT plants at $21 \mathrm{~d}$ of $-\mathrm{N}$ treatment (Fig. 1B).

CK PRODUCTION IN SAG12-IPT TRANSGENIC CREEPING Bentgrass IN RESPONSE TO $\mathbf{P}$ OR $\mathbf{N}$ DEFICIENCY. Differences between the SAG12-ipt plants and the NT control plants were identified for major CKs (iP/iPA, Z/ZR, and DHZ/DHZR) content in $-\mathrm{P}$ and $-\mathrm{N}$ treatments. No significant differences in leaf iP/iPA content were detected between the SAG12-ipt and NT lines when plants were grown in the complete nutrient solution $(0 \mathrm{~d})$ (Fig. 2A). The iP/iPA content of the NT plants decreased over time during $-\mathrm{P}$ treatment, whereas it was maintained in the SAG12-ipt plants. By $21 \mathrm{~d}$ of $-\mathrm{P}$ treatment, SAG12-ipt plants had significantly higher iP/iPA than the NT plants. In the $-\mathrm{N}$ treatment, $\mathrm{iP} / \mathrm{iPA}$ content of the NT line decreased at 7 and $21 \mathrm{~d}$, but the SAG12-ipt line maintained iP/ iPA content at the same level as at 0,7 , or $21 \mathrm{~d}$ of treatment. The SAG12-ipt line had significantly higher leaf iP/iPA content than the NT control line at 7 and $21 \mathrm{~d}$ of $-\mathrm{N}$ treatment.

Leaf DHZ/DHZR content was not significantly different between the two lines before imposing the nutrient deficiency treatments $(0 \mathrm{~d})$ (Fig. 2B). During $-\mathrm{P}$ treatment, DHZ/DHZR content of the SAG12-ipt plants increased significantly by $21 \mathrm{~d}$, almost doubling the content compared to $0 \mathrm{~d}$. The DHZ/DHZR content in the SAG12-ipt plants was significantly higher than in the NT line at $7 \mathrm{~d}$ and $21 \mathrm{~d}$ of $-\mathrm{P}$ treatment. $-\mathrm{N}$ treatment caused significant decline in DHZ/DHZR content in the NT control line at 7 and $21 \mathrm{~d}$. By $21 \mathrm{~d}$ of $-\mathrm{N}$ treatment, the SAG12-ipt plants had significantly higher DHZ/DHZR content than the NT plants.

Leaf Z/ZR content of the SAG12-ipt line was significantly higher than that of the NT line when grown in the complete nutrient solution prior to the $-\mathrm{N}$ and $-\mathrm{P}$ treatments $(0 \mathrm{~d})$ (Fig. $2 \mathrm{C})$. The NT plants showed decline in leaf Z/ZR content at $21 \mathrm{~d}$ of $-\mathrm{P}$ or $-\mathrm{N}$ treatments. At $7 \mathrm{~d}$ of $-\mathrm{P}$ treatment, leaf $\mathrm{Z} / \mathrm{ZR}$ content of the SAG12-ipt line was significantly higher than that of the NT line. At $7 \mathrm{~d}$ of $-\mathrm{N}$ treatment, there was no difference in $\mathrm{Z} / \mathrm{ZR}$ content between two lines. At $21 \mathrm{~d}$, leaf $\mathrm{Z} / \mathrm{ZR}$ content
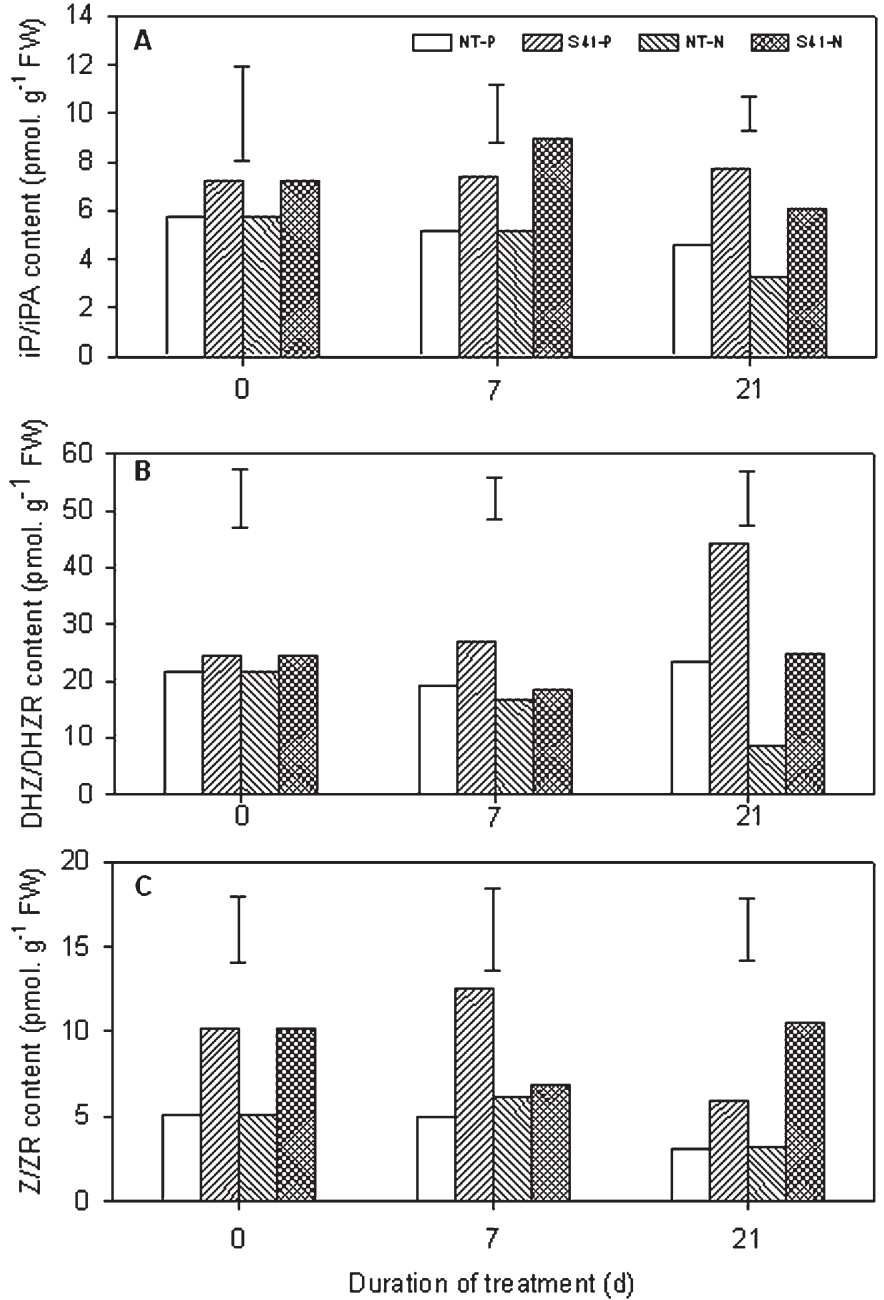

Fig. 2. Leaf isopentenyladenine/adenosine [iP/iPA (A)], dihydrozeatin/dihydrozeatin riboside [DHZ/DHZR (B)], and trans-zeatin/zeatin riboside [Z/ZR (C)] contents for SAG12-ipt transgenic line (S41) and the null transformant (NT) of creeping bentgrass at 0,7 , and $21 \mathrm{~d}$ of no nitrogen $(-\mathrm{N})$ or no phosphorus (-P) treatment. S41-P and S41-N denote S41 line grown in -P or $-\mathrm{N}$. NT-P and NT-N denote NT line in $-\mathrm{P}$ or $-\mathrm{N}$. LSD $(P=0.05)$ bars for comparisons of $\mathrm{iP} / \mathrm{iPA}, \mathrm{Z} / \mathrm{ZR}$, and DHZ/DHZR content among the treatments at a given date were present. $\operatorname{LSD}(P=0.05)$ values for comparisons of $\mathrm{iP} / \mathrm{iPA}$ content over time were $3.45,2.99,3.17$, and 3.70 for the S41-P, S41-N, NT-P, and NT-N, respectively. LSD $(P=0.05)$ values for comparisons of DHZ/DHZR content over time were 9.91, 12.27, 7.11, and 4.79 for the S41-P, S41-N, NT$\mathrm{P}$, and NT-N, respectively. LSD $(P=0.05)$ values for comparisons of $\mathrm{Z} / \mathrm{ZR}$ content over time were $6.13,5.75,2.66$, and 2.03 for the S41-P, S41-N, NT-P, and NT-N, respectively.

decreased in the NT line, but increased in the SAG12-ipt line, which resulted in significantly higher Z/ZR content in the ipttransgenic line than in the NT line.

Protein content, and NRase and APase activities in RESPONSE TO $\mathbf{P}$ AND N DEFICIENCY. One of the most rapid effects of nutrient deficiency treatments was the decline in leaf and root soluble protein content. Seven days after removing $\mathrm{N}$ or $\mathrm{P}$ from the culture media, leaf soluble protein content was $66 \% \pm$ $0.06 \%$ for the NT line and $54 \% \pm 0.05 \%$ for the $S A$ G 12 -ipt line in the $-\mathrm{P}$ treatment, and $61 \% \pm 0.08 \%$ for the NT line and $61 \% \pm$ $0.09 \%$ for the $S A G 12$-ipt line in the $-\mathrm{N}$ treatment compared to the protein content before nutrient removal (data not shown). Root soluble protein content, which was about $10 \%$ of leaf soluble protein content, also declined significantly in both 
treatments and both lines during the whole experiment period. It declined about $60 \%$ for the $-\mathrm{N}$ treatment in both lines, but the decline was much less in the-P-treated plants (data not shown).

APase activity in leaves did not change significantly at $7 \mathrm{~d}$, but increased in -P treatment for both lines at $21 \mathrm{~d}$ compared to that in plants supplied with $\mathrm{P}(0 \mathrm{~d})$ (Fig. $3 \mathrm{~A})$. In $-\mathrm{N}$ treatment, APase activity remained relatively unchanged in leaves during $21 \mathrm{~d}$ of treatment (Fig. 3A). No significant differences in APase activity in leaves were detected between the NT and the SAG12-ipt lines with or without $\mathrm{P}$ and $\mathrm{N}$ supply (Fig. 3A); however, APase activity in roots was significantly greater in the SAG12-ipt line at 7 and $21 \mathrm{~d}$ of $-\mathrm{P}$ treatment and at $7 \mathrm{~d}$ of $-\mathrm{N}$ treatment (Fig. 3B). At $21 \mathrm{~d}$ of $-\mathrm{P}$ treatment, root APase was more than two times higher in the SAG12-ipt line than in the NT line.

Leaf NRase activity declined significantly in SAG12-ipt and NT plants at 7 and $21 \mathrm{~d}$ of $-\mathrm{N}$ and $-\mathrm{P}$ treatments (Fig. 4A). No significant differences in leaf NRase activity were detected between the two lines at 7 or $21 \mathrm{~d}$ of -P treatment, but a higher leaf NRase was found in the SAG12-ipt line than in the NT line at $7 \mathrm{~d}$ of $-\mathrm{N}$ treatment (Fig. 4A). Root NRase activity also declined at 7 and $21 \mathrm{~d}$ of $-\mathrm{P}$ or $-\mathrm{N}$ treatment, but did not differ between the two lines at 7 or $21 \mathrm{~d}$ in $-\mathrm{P}$ or $-\mathrm{N}$ treatment (Fig. 4B).
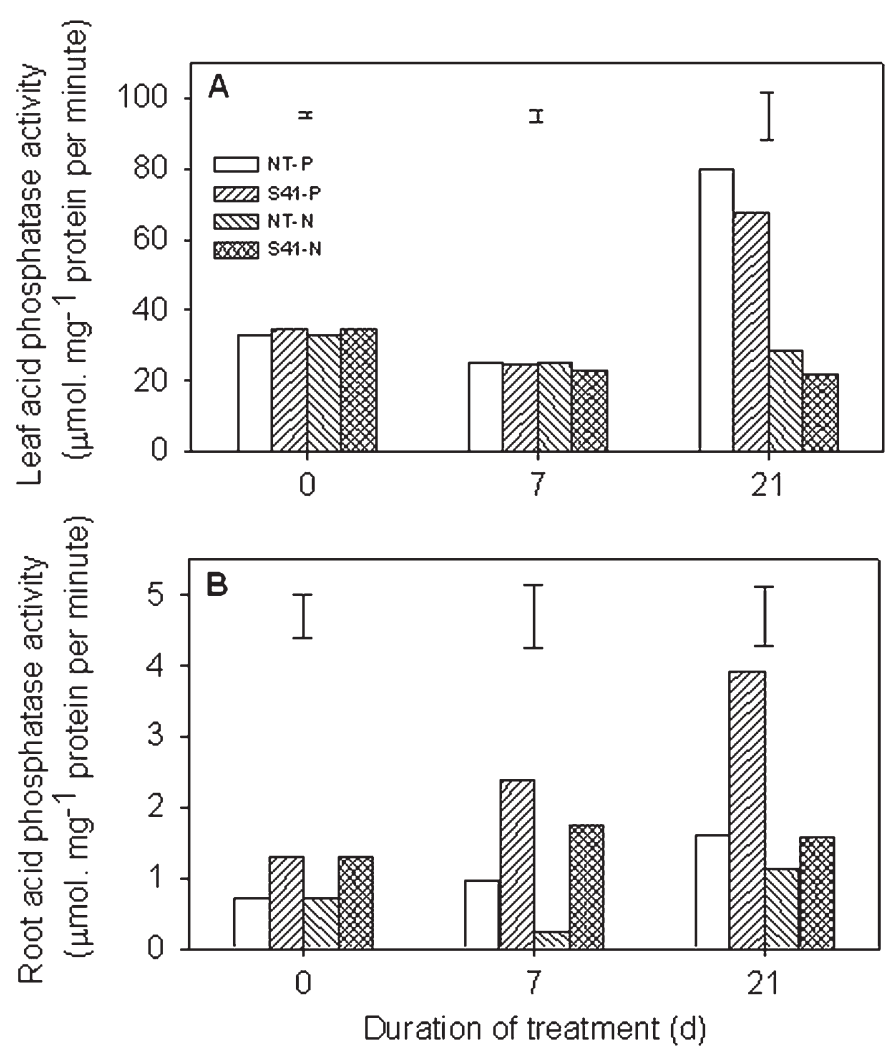

Fig. 3. Acid phosphatase (APase) activity for SAG12-ipt transgenic line (S41) and the null transformant line (NT) of creeping bentgrass in leaf (A) or in root (B) at 0,7 , and $21 \mathrm{~d}$ of no nitrogen $(-\mathrm{N})$ or no phosphorus $(-\mathrm{P})$ treatment. LSD $(P=0.05)$ bars for comparisons of APase activity among the treatments at a given date were present. LSD $(P=0.05)$ values for comparisons of APase activity in leaves over time were 4.36, 3.05, 4.07, and 2.04 for the S41-P, S41N, NT-P, and NT-N, respectively. LSD $(P=0.05)$ values for comparisons of APase activity in roots over time were $0.60,1.35,0.65$, and 0.52 for the S41-P, S41-N, NT-P, and NT-N, respectively.
EXPRESSION OF IPT IN LEAVES. RT-PCR was conducted to determine if SAG12-ipt expression would occur in $-\mathrm{N}$ or $-\mathrm{P}$ treatment. A primer pair specific to the ipt gene sequence was able to amplify a 520-bp fragment from leaves of SAG12-ipt plants (Fig. 5). Sequencing of this fragment confirmed the identity of ipt gene (data not shown). No amplification was observed from the NT line using the ipt gene-specific primers. RT-PCR conducted without reverse transcriptase also did not give any amplification, which suggested no presence of DNA contamination (data not shown). Amplification of ipt in the SAG12-ipt line was detected prior to and during $-\mathrm{N}$ or $\mathrm{P}$ treatment. A lower expression of ipt was observed in $-\mathrm{N}$-treated
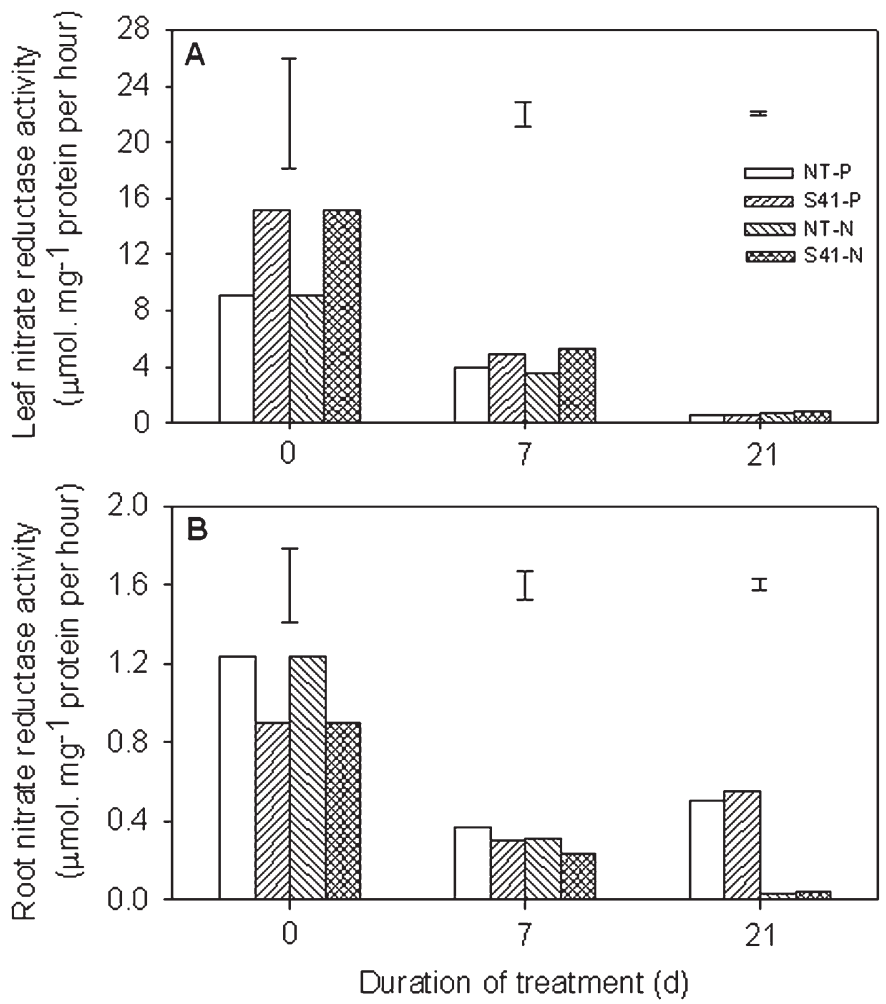

Fig. 4. Nitrate reductase (NRase) activity for SAG12-ipt transgenic line (S41) and the null transformant line (NT) of creeping bentgrass in leaf (A) or in root (B) at 0,7 , and $21 \mathrm{~d}$ of no nitrogen $(-\mathrm{N})$ or no phosphorus $(-\mathrm{P})$ treatment. LSD $(P=0.05)$ bars for comparisons of APase activity among the treatments at a given date were present. LSD $(P=0.05)$ values for comparisons of NRase activity in leaves over time were $0.01,0.02,0.01$, and 0.01 for the S41-P, S41$\mathrm{N}$, NT-P, and NT-N, respectively. LSD $(P=0.05)$ values for comparisons of NRase activity in roots over time were $0.02,0.01,0.005$, and 0.008 for the S41-P, S41-N, NT-P, and NT-N, respectively.

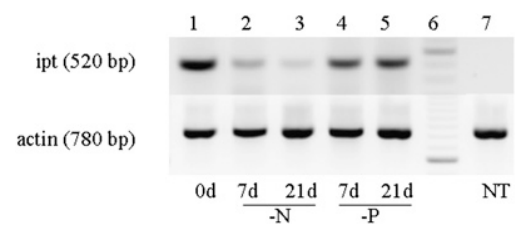

Fig. 5. RT-PCR analysis of ipt expression in the leaf of SAG12-ipt transgenic line (S41) and the null transformant line (NT) of creeping bentgrass at 0,7 , and $21 \mathrm{~d}$ of no nitrogen $(-\mathrm{N})$ or no phosphorus $(-\mathrm{P})$ treatment. Lane 1: before $-\mathrm{N}$ or $-\mathrm{P}$, Lane $2: 7 \mathrm{~d}$ in $-\mathrm{N}$, Lane 3: $21 \mathrm{~d}$ in $-\mathrm{N}$, Lane $4: 7 \mathrm{~d}$ in $-\mathrm{P}$, Lane $5: 21 \mathrm{~d}$ in $-\mathrm{P}$, Lane 6: 100-bp DNA ladder $(0.2 \mu \mathrm{g})$, Lane 7: NT in complete nutrient solution. Equal expression of actin gene was used as an internal standard. Ten and $3 \mu \mathrm{L}$ of PCR products were loaded in the $1.5 \%$ agarose gel for ipt and actin gene, respectively, to minimize the difference of the signal intensity of the PCR products. 
than in -P-treated plants. The difference in the level of ipt expression during the $-\mathrm{N}$ time course was greatest at $21 \mathrm{~d}$.

\section{Discussion}

Leaf photochemical efficiency and chlorophyll content are commonly used indicators for leaf senescence (Lim et al., 2007). In this study, $-\mathrm{N}$ and $-\mathrm{P}$ treatments induced leaf senescence in NT plants, as demonstrated by the decline in both parameters, particularly in the $-\mathrm{N}$ treatment. However, leaf senescence was delayed and suppressed significantly in SAG12-ipt plants under $-\mathrm{N}$ and -P conditions, indicating that transformation of creeping bentgrass with ipt expression enabled plants to retain more chlorophyll and higher photosynthetic activity associated with the regulation of leaf senescence. In addition, leaf senescence was more severe in -N- than in -Ptreated plants for both lines, suggesting that perennial grass plants were more susceptible to $\mathrm{N}$ than to $\mathrm{P}$ deficiency.

The suppression of $-\mathrm{N}$ - or $-\mathrm{P}$-induced leaf senescence in the SAG12-ipt plants was associated with ipt expression and accumulation of CKs. The NT plants exhibited decline in $\mathrm{iP} / \mathrm{iPA}$ and $\mathrm{Z} / \mathrm{ZR}$ contents at $21 \mathrm{~d}$ of $-\mathrm{N}$ or $-\mathrm{P}$ treatment in comparison to that prior to nutrient starvation $(0 \mathrm{~d})$, which is consistent with previous reported results in other plant species that $\mathrm{N}$ or $\mathrm{P}$ deficiency results in reduction of $\mathrm{CK}$ content (Schachtman and Shin, 2007). However, the SAG12-ipt plants were able to maintain $\mathrm{CK}$ content under $\mathrm{N}$ or $\mathrm{P}$ deficiency, suggesting that ipt expression may activate mechanisms that counteract the inhibitory effects of $\mathrm{N}$ or $\mathrm{P}$ deficiency on $\mathrm{CK}$ accumulation. In addition, SAG12-ipt plants exhibited significantly higher levels of all three forms of CKs in leaves, particularly iP/iPA than the NT plants under $-\mathrm{N}$ and $-\mathrm{P}$ treatments. The most dramatic difference between the NT and SAG12-ipt lines was observed in $\mathrm{iP} / \mathrm{iPA}, \mathrm{DHZ} / \mathrm{DHZR}$, and Z/ ZR levels at $21 \mathrm{~d}$ for both nutrient deficiency treatments. SAG12-ipt plants in our study had two to three times the CK content of the NT plants under $-\mathrm{N}$ or $-\mathrm{P}$ conditions despite decreased ipt transcription relative to the expression level prior to $-\mathrm{N}$ or $-\mathrm{P}$ treatment. Although the SAG12 was designed as a senescence-induced promoter (Gan and Amasino, 1995), the expression of SAG12-ipt grown under non-stress conditions has been detected in various plant species (Huynh et al., 2005; Swartzberg et al., 2006; Sykorová et al., 2008). The ipt gene driven by the senescence-induced monocotyledonous promoter SEE1 also showed basal expression (Li et al., 2004). Creeping bentgrass is a perennial grass with sequential leaf formation, maturation, and senescence. Therefore, the increases in CK content and expression of SAG12-ipt in transgenic creeping bentgrass prior to nutrient deficiency may be caused by natural senescence because some fully expanded, mature leaves may have begun senescing, thereby activating SAG12-ipt. In addition, plants were cut to maintain a uniform canopy height during the establishment phase prior to exposure to $-\mathrm{N}$ or $-\mathrm{P}$ treatment. Wounding from cutting may cause cell senescence, resulting in the activation of $S A G 12$. Leaf senescence, particularly at its initial stage, is subjected to regulation by external factors, including wounding (Gan and Amasino, 1997). The lower expression of ipt in $-\mathrm{N}$ or $-\mathrm{P}$ plants with prolonged periods $(21 \mathrm{~d})$ of stress was consistent with the results obtained in tobacco by Rivero et al. (2007), where they reported decreased ipt expression under drought stress, but increased CK content in the SAG12-ipt plants even with lower ipt expression. Such changes in ipt expression under nutrient deficiency could be the result of the autoregulatory effects of the senescence-inducible promoters. Gan and Amasino (1995) estimated that the autoregulation system from the senescenceinducible promoter might cause reduction in ipt expression level by over 1000-fold. Nevertheless, the increase in CK content in SAG12-ipt plants correlated with the maintenance in $\mathrm{Fv} / \mathrm{Fm}$ and chlorophyll content, suggesting that elevated CK production may have suppressed leaf senescence due to leaf maturation or induced by stresses, particularly following prolonged periods of $\mathrm{N}$ or $\mathrm{P}$ nutrient starvation.

Higher APase activity was found in leaves (Trull et al., 1997; Yan et al., 2001; Yun and Kaeppler, 2001) and roots (Ni et al., 1996; Tadano and Sakai, 1991) under P deficiency. Enhanced APase may be an indication of $\mathrm{P}$ deficiency or a mechanism of plant adaptation to $\mathrm{P}$ deprivation, where APase remobilizes $\mathrm{P}$ from metabolically less active mature or senescent leaves to young or developing tissues (Schachtman et al., 1998). Nevertheless, a marked increase in leaf APase activity was observed at $21 \mathrm{~d}$ of treatment. Therefore, the higher leaf APase activity may indeed be associated with a survival strategy against low nutrient availability by increasing the utilization efficiency of $\mathrm{P}$, thus, increased APase activity may accelerate remobilization of $\mathrm{P}$ from older to younger leaves under P-limiting conditions. The response of root APase activity in the SAG12-ipt line differed between the $-\mathrm{P}$ - and $-\mathrm{N}$-treated plants. There was a clear activation of APase in -P-treated roots in both lines, whereas the induction of APase was not detected in the $-\mathrm{N}$ treatment in either line (Fig, 3B), suggesting a specific effect of -P treatment on APase activity. Roots of the SAG12-ipt line had two to three times higher APase activity compared to the NT line in $-\mathrm{P}$ and $-\mathrm{N}$ treatments, which could indicate that roots were metabolically more active in the SAG12-ipt line or that increased CKs in the SAG12-ipt line may help maintain root APase activity under P or N deficiency. Sakakibara et al. (2006) pointed out in a recent review that $\mathrm{CKs}$ play a key role in regulating macronutrient acquisition, although the underlying mechanisms are not fully understood. Nevertheless, higher APase activity in the SAG12-ipt line indicated that these plants might have better $\mathrm{P}$ utilization efficiency under low nutrient supply.

Because nitrate is assimilated via conversion to nitrite by NRase, then to ammonium and into amino acids, it has been suggested that the internal pools of amino acids within plants may indicate $\mathrm{N}$ status by providing a signal that can regulate nitrate uptake by the plant (Solomonson and Barber, 1990). NRase activity declined in $-\mathrm{N}$ or $-\mathrm{P}$ treatment in NT control and SAG12-ipt plants, suggesting that reduced nitrate assimilation or uptake may have occurred under $\mathrm{N}$ or $\mathrm{P}$ deficiency, which is in agreement with previous report in other plant species that NRase activity is affected by $\mathrm{N}$ or $\mathrm{P}$ availability (Jiang and Hull, 1998; Rufty et al., 1993). Rufty et al. (1993) reported that decreases in nitrate uptake in low $\mathrm{P}$ soybean (Glycine max) were caused by feedback factors or limited ATP availability. NRase activity, however, may be induced by increasing nitrate and CKs supply (Kende and Shen, 1972). Enhanced NRase activity was found by exogenous CK application (Gaudinova, 1990). Therefore, it could be expected that NRase activity may be higher in tissues with higher CK content (Banowetz, 1992). Our data, however, demonstrated that ipt expression did not have effects on NRase in leaves or roots, but NRase declined with $-\mathrm{P}$ or $-\mathrm{N}$ treatment. These results suggest that NRase was more sensitive to changes in $\mathrm{N}$ or $\mathrm{P}$ supply than 
$\mathrm{CK}$ content in creeping bentgrass, and the suppressed leaf senescence in SAG12-ipt plants with elevated CK content under $\mathrm{N}$ deficiency was not associated with $\mathrm{CK}$ regulation of NRase in creeping bentgrass. NRase activity in leaves was several times higher than that in roots in all plants, regardless of nutrient treatments, suggestive of higher nitrogen reduction activity or reflective of higher demand of $\mathrm{N}$ of leaves relative to roots.

In summary, $\mathrm{N}$ or $\mathrm{P}$ deficiency induced leaf senescence in creeping bentgrass, to a greater extent with $\mathrm{N}$ deficiency than with $\mathrm{P}$ deficiency. The expression of SAG12-ipt in creeping bentgrass resulted in suppression of low $\mathrm{N}$ - or low P-induced leaf senescence, as manifested by the higher levels of Fv/Fm and chlorophyll content in the transgenic plants. The senescence suppression was associated with the maintenance of higher CKs (Z/ZR, DHZ/DHZR, and iP/iPA) content in leaves, despite the decreased level of ipt expression under $\mathrm{N}$ or $\mathrm{P}$ deficiency, as the $S A G 12$ promoter could be autoregulated. The increased level of $\mathrm{CKs}$ in SAG12-ipt bentgrass plants may promote more efficient use of $\mathrm{P}$, as shown by enhanced acid phosphatase activity in roots under $-\mathrm{P}$ conditions. Various other mechanisms may be involved in $\mathrm{CK}$ regulation of leaf senescence associated with nutrient deficiency, such as changes in antioxidant and protein metabolisms, which requires further investigation. In addition, the lack of differences in NRase between SAG12-ipt and the non-transgenic plants suggested that nitrate reductase may play a minor role, while other factors such as organic nitrogen metabolism and $\mathrm{N}$ remobilization may be involved in CK regulation of leaf senescence under nitrogendeficient conditions, which deserves further investigation.

\section{Literature Cited}

Arnon, D.I. 1949. Copper enzymes in isolated chloroplasts. Polyphenoloxidase in Beta vulgaris. Plant Physiol. 24:1-13.

Banowetz, G.M. 1992. The effects of endogenous cytokinin content on benzyladenine-enhanced nitrate reductase induction. Physiol. Plant. 86:341-348.

Bradford, M.M. 1976. A rapid and sensitive method for the quantitative of microgram quantities of protein utilizing the principle of protein-dye binding. Anal. Biochem. 72:248-254.

Calderini, O., T. Bovone, C. Scotti, F. Pupilli, E. Piano, and S. Arcioni. 2007. Delay of leaf senescence in Medicago sativa transformed with the ipt gene controlled by the senescence-specific promoter SAG12. Plant Cell Rep. 26:611-615.

Chang, H., M. Jones, G.M. Banowetz, and D.G. Clark. 2003. Overproduction of cytokinins in petunia flowers transformed with PSAG12-IPT delays corolla senescence and decreases sensitivity to ethylene. Plant Physiol. 132:2174-2183.

Chen, L.F.O., J.Y. Hwang, Y.Y. Charng, C.W. Sun, and S.F. Yang. 2001. Transformation of broccoli (Brassica oleracea var. italica) with isopentenyltransferase gene via Agrobacterium tumefaciens for post-harvest yellowing retardation. Mol. Breed. 7:243-257.

Clark, D.G., C. Dervinis, J.E. Barret, H. Klee, and M. Jones. 2004. Drought-induced leaf senescence and horticultural performance of transgenic P-SAG12-IPT petunias. J. Amer. Soc. Hort. Sci. 129:9399.

Clarkson, D.T. and U. Lüttge. 1991. Mineral nutrition: Inducible and repressible nutrient transport system. Prog. Bot. 52:61-83.

Cowan, A.K., M. Freeman, P.O. Bjorkman, B. Nicander, F. Sitbon, and E. Tillberg. 2005. Effects of senescence-induced alteration in cytokinin metabolism on source-sink relationships and ontogenic stress-induced transitions in tobacco. Planta 221:801-814.

Duff, S.M.G., G. Sarath, and W.C. Plaxton. 1994. The role of acid phosphatases in plant phosphorus metabolism. Physiol. Plant. 90:791-800.
Eberle, J., A. Arnscheidt, D. Klix, and E.W. Weiler. 1986. Monoclonal antibodies to plant growth regulators: III. Zeatinriboside and dihydrozeatinriboside. Plant Physiol. 81:516-521.

Gan, S.S. and R.M. Amasino. 1995. Inhibition of leaf senescence by autoregulated production of cytokinin. Science 270:1986-1988.

Gan, S.S. and R.M. Amasino. 1996. Cytokinins in plant senescence: From spray and pray to clone and play. Bioessays 18:557-565.

Gan, S.S. and R.M. Amasino. 1997. Making sense of senescence (molecular genetic regulation and manipulation of leaf senescence). Plant Physiol. 113:313-319.

Gaudinova, A. 1990. The effect of cytokinins on nitrate reductase activity. Biol. Plant. 32:89-96.

Hoagland, C.R. and D.I. Arnon. 1950. The solution-culture method for growing plants without soil. California Agr. Expt. Circ. 347.

Hu, Y.L., W.L. Jia, J.D. Wang, Y.Q. Zhang, L.L. Yang, and Z.P. Lin. 2005. Transgenic tall fescue containing the Agrobacterium tumefaciens ipt gene shows enhanced cold tolerance. Plant Cell Rep. 23: 705-709.

Huynh, L.N., T. VanToai, J. Streeter, and G. Banowetz. 2005. Regulation of flooding tolerance of SAG12:ipt Arabidopsis plants by cytokinin. J. Expt. Bot. 56:1397-1407.

Jiang, Z. and R.J. Hull. 1998. Interrelationships of nitrate uptake, nitrate reductase, and nitrogen use efficiency in selected kentucky bluegrass cultivars. Crop Sci. 38:1623-1632.

Jordi, W., A. Schapendonk, E. Davelaar, G.M. Stoopen, C.S. Pot, R. De Visser, J.A. Van Rhijn, S. Gan, and R.M. Amasino. 2000. Increased cytokinin levels in transgenic $\mathrm{P}_{\mathrm{SAG} 12}-I P T$ tobacco plants have large direct and indirect effects on leaf senescence, photosynthesis and N partitioning. Plant Cell Environ. 23:279-289.

Kaiser, W.M. and E. Brendle-Behnisch. 1991. Rapid modulation of spinach leaf nitrate reductase activity by photosynthesis. I. Modulation in vivo by $\mathrm{CO}_{2}$ availability. Plant Physiol. 96:363-367.

Kende, H. and T.C. Shen. 1972. Nitrate reductase in Agrostema githago: Comparison of inductive effects of nitrate and cytokinin. Biochim. Biophys. Acta 286:118-125.

Khodakovskaya, M., Y. Li, J.S. Li, R. Vankova, J. Malbeck, and R. McAvoy. 2005. Effects of cor15a-IPT gene expression on leaf senescence in transgenic Petunia $\times$ hybrida and Dendranthema $\times$ grandiflorum. J. Expt. Bot. 56:1165-1175.

Li, Q., P.R.H. Robson, A.J.E. Bettany, I.S. Donnison, H. Thomas, and I.M. Scott. 2004. Modification of senescence in ryegrass transformed with IPT under the control of a monocot senescence-enhanced promoter. Plant Cell Rep. 22:816-821.

Lim, P.O., H.J. Kim, and H.G. Nam. 2007. Leaf senescence. Annu. Rev. Plant Biol. 58:115-136.

Lin, Y.J., M.L. Cao, C.G. Xu, H. Chen, J. Wei, and Q.F. Zhang. 2002. Cultivating rice with delaying leaf-senescence by P-SAG12-IPT gene transformation. Acta Bot. Sin. 44:1333-1338.

Mayak, S. and A.H. Halevy. 1970. Cytokinin activity in rose petals and its relation to senescence. Plant Physiol. 46:497-499.

McCabe, M.S., L.C. Garratt, F. Schepers, W.J.R.M. Jordi, G.M. Stoopen, E. Davelaar, J.H.A. van Rhijn, J.B. Power, and M.R. Davey. 2001. Effects of $\mathrm{P}_{\mathrm{SAG} 12-I P T}$ gene expression on development and senescence in transgenic lettuce. Plant Physiol. 127:505-516.

McGrady, J.J., P.C. Struik, and E.E. Ewing. 1986. Effects of exogenous application of cytokinin on the development of potato (Solanum tuberosum L.) cuttings. Potato Res. 29:191-205.

McLachlan, K.D., D.E. Elliott, D.G. De Marco, and J.H. Garran. 1987. Leaf acid phosphatase isozymes in the diagnosis of phosphorus status in field-grown wheat. Aust. J. Agr. Res. 38:1-13.

Medford, J.I., R. Horgan, Z. El-Sawi, and H.J. Klee. 1989. Alteration of endogenous cytokinins in transgenic plants using a chimeric isopentenyl transferase gene. Plant Cell 1:403-413.

Ni, J.J., P. Wu, A.C. Lou, Y.S. Zhang, and Q.N. Tao. 1996. Low phosphorus effects on the metabolism of rice seedling. Commun. Soil Sci. Plant. 27:3073-3084.

Rivero, R.M., M. Kojima, A. Gepstein, H. Sakakibara, R. Mittler, S. Gepstein, and E. Blumwald. 2007. Delayed leaf senescence induces 
extreme drought tolerance in a flowering plant. Proc. Natl. Acad. Sci. USA 104:19631-19636.

Rufty, T.W., D.W. Israel, R.J. Volk, J. Qiu, and T. Sa. 1993. Phosphate regulation of nitrate assimilation in soybean. J. Expt. Bot. 44:879891.

Sakakibara, H., K. Takei, and N. Hirose. 2006. Interactions between nitrogen and cytokinin in the regulation of metabolism and development. Trends Plant Sci. 11:440-448.

Sambrook, J., E.F. Fritsch, and T. Maniatis. 1989. Molecular cloning: A laboratory manual. Cold Spring Harbor Press, Plainview, NY.

Schachtman, D.P. and R. Shin. 2007. Nutrient sensing and signaling: NPKS. Annu. Rev. Plant Biol. 58:47-69.

Schachtman, D.P., R.J. Reid, and S.M. Ayling. 1998. Phosphorus uptake by plants: From soil to cell. Plant Physiol. 116:447-453.

Schnablova, T., H. Synkova, A. Vicankova, L. Burketova, J. Eder, and M. Cvikrova. 2006. Transgenic ipt tobacco overproducing cytokinins overaccumulates phenolic compounds during in vitro growth. Plant Physiol. Biochem. 44:526-534.

Setter, T.L., B.A. Flannigan, and J. Melkonian. 2001. Loss of kernel set due to water deficit and shade in maize: Carbohydrate supplies, abscisic acid, and cytokinins. Crop Sci. 41:1530-1540.

Singh, S., D.S. Letham, and M.S. Palni. 1992. Cytokinin biochemistry in relation to leaf senescence: VII. Endogenous cytokinin levels and exogenous applications of cytokinins in relation to sequential leaf senescence of tobacco. Physiol. Plant. 86:388-397.

Smart, C.M. 1994. Gene expression during leaf senescence. New Phytol. 126:419-448.

Solomonson, L.P. and M.J. Barber. 1990. Assimilatory nitrate reductase: Functional properties and regulation. Annu. Rev. Plant Physiol. Plant Mol. Biol. 41:225-253.

Swartzberg, D., N. Dai, S. Gan, R. Amasino, and D. Granot. 2006. Effects of cytokinin production under two SAG promoters on senescence and development of tomato plants. Plant Biol. 8:579586.
Sykorová, B., G. Kuresová, S. Daskalova, M. Trcková, K. Hoyerová, I. Raimanová, V. Motyka, A. Trávnícková, M.C. Elliott, and M. Kamínek. 2008. Senescence-induced ectopic expression of the A. tumefaciens ipt gene in wheat delays leaf senescence, increases cytokinin content, nitrate influx, and nitrate reductase activity, but does not affect grain yield. J. Expt. Bot. 59:377-387.

Tadano, T. and H. Sakai. 1991. Secretion of acid phosphatase by the roots of several crop species under phosphorus-deficient conditions. Soil Sci. Plant Nutr. 37:129-140.

Thomas, H. and J.L. Stoddart. 1980. Leaf senescence. Annu. Rev. Plant Physiol. 31:83-111.

Trull, M.C., M.J. Guiltinan, J.P. Lynch, and J. Deikman. 1997. The responses of wild type and ABA mutant Arabidopsis thaliana plants to phosphorus starvation. Plant Cell Environ. 20:85-92.

Wang, Z., J. Pote, and B. Huang. 2003. Responses of cytokinins, antioxidant enzymes, and lipid peroxidation in shoots of creeping bentgrass to high root-zone temperatures. J. Amer. Soc. Hort. Sci. 128:648-655.

Xu, Y., J. Tian, T. Gianfagna, and B. Huang. 2009. Effects of SAG12ipt expression on cytokinin production, growth and senescence of creeping bentgrass (Agrosis stolonifera L.) under heat stress. Plant Growth Regulat. 57:281-291.

Yan, X., H. Liao, M.C. Trull, S.E. Beebe, and J.P. Lynch. 2001. Induction of a major leaf acid phosphatase does not confer adaptation to low phosphorus availability in common bean. Plant Physiol. 125:1901-1911

Yun, S.J. and S.M. Kaeppler. 2001. Induction of maize acid phosphatase activity under phosphorus starvation. Plant Soil 237:109-115.

Zhang, J., T. Van Toai, L. Huynh, and J. Preiszner. 2000. Development of flooding-tolerant Arabidopsis thaliana by autoregulated cytokinin production. Mol. Breed. 6:135-144.

Zhang, X.Z. and E.H. Ervin. 2008. Impact of seaweed extract-based cytokinins and zeatin riboside on creeping bentgrass heat tolerance. Crop Sci. 48:364-370. 